\title{
A biblioteca universitária e sua atuação frente à mutabilidade de paradigmas
}

\author{
The academic library and its action towards the mutability of paradigms
}

\begin{abstract}
Lílian Lima de Siqueira Melo
Mestre em Gestão Pública para o Desenvolvimento do Nordeste. Bibliotecária especialista em Gestão e Tecnologia da Informação da Universidade Federal de Pernambuco.

E-mail: $\underline{\text { liliamelo@gmail.com }}$

Denílson Bezerra Marques

Doutor em Sociologia pela Universidade Federal de Pernambuco - UFPE. Professor Adjunto da Universidade Federal de Pernambuco. E-mail: marquesdb@gmail.com.

Fabio Assis Pinho

Doutor em Ciência da Informação pela Universidade Estadual Paulista - UNESP, campus de Marília. Professor Adjunto do Departamento de Ciência da Informação e do Programa de Pós-Graduação em Ciência da Informação da Universidade Federal de Pernambuco - UFPE.

E-mail: fabiopinho@ufpe.br
\end{abstract}

\begin{abstract}
Resumo
Esta pesquisa teve como objetivo analisar de que maneira os gestores do SIB/UFPE planejam os produtos e serviços ofertados, bem como a força de trabalho, diante dos paradigmas da informação e do acervo. Trata-se de uma pesquisa exploratória de caráter descritivo e aplicado. O campo de pesquisa é na Universidade Federal de Pernambuco (UFPE), em específico, no Sistema Integrado de Bibliotecas (SIB). A população estudada é composta por 13 gestores do Sistema e utiliza como instrumento de coleta de dados a entrevista semiestruturada. Os dados da pesquisa foram analisados de forma qualitativa pela técnica de análise de conteúdo. Os resultados obtidos revelam que as bibliotecas do SIB possuem características de atuação tanto do paradigma do acervo como do paradigma da informação, porém algumas características demonstram que paradigma do acervo ainda é dominante.
\end{abstract}

Palavras-chave: Bibliotecas universitárias. Gestão de bibliotecas. Paradigma do Acervo. Paradigma da informação

\begin{abstract}
This research aims to analyze how the managers of SIB / UFPE plan products and services offered, as well as the labor force before the paradigms of information and collections. This is an exploratory research, descriptive and applied. The research is at the Federal University of Pernambuco (UFPE), in particular the Integrated Library System (SIB). The study population consists of 13 managers the System and use as a tool for data collection semistructured interview. The survey data were analyzed by qualitative content analysis technique. The results show that libraries have the SIB performance characteristics of both the paradigm of the collection as the paradigm of information, however some features demonstrate that of the collection paradigm is still dominant.
\end{abstract}

Keywords: University libraries. Management of libraries. Paradigm of collection. Paradigm of information. 


\section{Introdução}

As Tecnologias da Informação e Comunicação (TIC's) estão mudando as bibliotecas. O cenário atual mostra que as mudanças são rápidas e que as unidades de informação precisam se adaptar a nova realidade. Até pouco tempo atrás os acervos das bibliotecas ocupavam espaços enormes nas estantes, hoje se sabe que muitos cabem em suportes cada vez menores. Os serviços oferecidos podem ser disponibilizados não apenas de forma presencial como também pela internet em redes sociais, $\log s$, sítios e outros veículos de comunicação (MORIGI; SOUTO, 2005).

Até a década de 60 a preocupação de quem administrava as bibliotecas era em acumular a produção bibliográfica porque o foco dos gestores naquele momento estava voltado à oferta de documentos e também ao acúmulo e desenvolvimento físico das coleções. Era sinal de status a biblioteca ser depositária de toda a produção intelectual da época. Esta forma de atuação é característica do paradigma centrado no acervo.

Nos $\operatorname{anos} 70$, com a explosão bibliográfica e a evolução das TIC's, houve a impossibilidade das bibliotecas abarcarem toda a produção intelectual gerada e diante disso não conseguiam suprir todas as necessidades dos usuários com recursos próprios devido às restrições orçamentárias. Deste modo, nas décadas seguintes as bibliotecas começaram a compartilhar informações e o foco deixa de ser a acumulação de acervos e volta-se para o acesso às informações independente de sua localização física e de acordo com as necessidades dos usuários. Logo, a forma de atuação começa a mudar na perspectiva de um novo paradigma, o paradigma do acesso à informação (DIAS, 2003; SARACEVIC, 1995).

Essa nova configuração leva as bibliotecas a reflexão sobre os paradigmas até então estabelecidos e o nascimento de novos paradigmas que abarcam "uma nova visão da práxis, incorporando novos temas prioritários, novas técnicas e métodos, novas hipóteses e teorias, num ciclo contínuo e permanente, e mais do que isto, inesgotável" (TARGINO, 2010, p. 41). Neste sentido, surge o tema deste trabalho que versa sobre o Sistema Integrado de Bibliotecas da UFPE (SIB/UFPE) e sua atuação frente à mutabilidade dos paradigmas.

A questão problematizadora desta pesquisa está centrada em estudar como o Sistema Integrado de Bibliotecas da Universidade Federal de Pernambuco (SIB/UFPE) se comporta frente aos paradigmas, ou seja, sua atuação está voltada para a perspectiva tradicional do paradigma do acervo ou para a perspectiva moderna do paradigma da informação?

InCID: R. Ci. Inf. e Doc., Ribeirão Preto, v. 5, n. 1, p. 69-89, mar./ago. 2014. 
Por isso, a população pesquisada foi composta pelos gestores das Bibliotecas que integram o SIB/UFPE. Sendo assim, este trabalho se justifica pela necessidade de estudos que enfoquem o papel das bibliotecas como provedoras de serviços de informação aos seus usuários com vistas à inclusão destes num ambiente onde as informações são compartilhadas e acessadas de tal maneira que possibilita a transmissão do saber e a troca de conhecimentos entre os indivíduos.

Nesse sentido, a pesquisa contribui para um direcionamento da atuação (força de trabalho) e do investimento (financeiro) das Bibliotecas da UFPE face aos paradigmas do acervo e da informação e, a partir dos resultados, propõe diretrizes para subsidiar a gestão destas unidades frente às necessidades atuais dos seus usuários.

Portanto, foi delineado como objetivo geral da pesquisa: analisar de que maneira os gestores do SIB/UFPE planejam os produtos e serviços ofertados, bem como a força de trabalho, diante dos paradigmas da informação e do acervo. Desse modo, de forma específica tem-se: a) realizar um levantamento dos produtos/serviços oferecidos face aos paradigmas do acervo e da informação; b) observar a gestão desses produtos/serviços frente aos paradigmas; c) analisar como os gestores direcionam a força de trabalho dos profissionais bibliotecários que atuam no SIB e; d) verificar a qualidade dos investimentos financeiros nas bibliotecas.

\section{Bibliotecas, paradigmas e implicações}

O termo paradigma se origina do grego "significa exemplo, ou melhor, ainda, modelo ou padrão" (GONZÁLEZ, 2005, p. 3). Numa abordagem filosófica da ciência, defendida por Kuhn (2003), entende-se paradigma como um conjunto de realizações científicas reconhecidas por uma determinada comunidade, durante certo período, fornecendo problemas e soluções modelares que podem ser identificados no seu campo de atuação. No âmbito da ciência da informação, Capurro (2003) compreende paradigma como um modelo abstrato que possibilita ver uma coisa em analogia à outra.

Castells afirma que atualmente uma nova dinâmica social está se constituindo dentro de um novo paradigma conhecido como paradigma da informação, ele é responsável por formar a base material da sociedade da informação, nele:

Informação é matéria prima: as tecnologias agem sobre a informação, não apenas informação age sobre tecnologia, como as revoluções tecnológicas anteriores;

InCID: R. Ci. Inf. e Doc., Ribeirão Preto, v. 5, n. 1, p. 69-89, mar./ago. 2014. 
A penetrabilidade dos efeitos das novas tecnologias: a informação é parte integral de toda atividade humana, todos os processos de nossa existência individual e coletiva são diretamente moldados (embora, não determinados) pelo novo meio tecnológico;

A lógica de redes em qualquer sistema: essa configuração topológica, a rede, agora pode ser implementada materialmente em todos os tipos de processos e organizações graças a recentes tecnologias da informação;

A flexibilidade: não apenas os processos são reversíveis, mas organizações e instituições podem ser modificadas, e fundamentalmente alteradas, pela reorganização de seus componentes. O que distingue a configuração do novo paradigma tecnológico é sua capacidade de reconfiguração, um aspecto decisivo em uma sociedade caracterizada por constante mudança e fluidez organizacional;

A crescente convergência de tecnologias específicas para um sistema altamente integrado: a microeletrônica, as telecomunicações, a optoeletrônica e os computadores são todos integrados nos sistemas de informação. Em termos de sistemas tecnológicos, um elemento não pode ser imaginado sem o outro (CASTELLS, $1999^{1}$ apud SANTOS 2010, p. 23, grifo do autor).

Coelho Netto (1996) ainda no século XX, estabeleceu para a biblioteconomia uma mudança de paradigmas: o paradigma do acervo para o paradigma da informação. Nesta nova configuração, a informação passa a ser o objeto de estudo, utilizando-se das novas tecnologias como motor propulsor das mudanças.

De acordo com Targino (2010), o aparecimento das TIC's nos anos 60 e 70 provocou profundas alterações na mudança de paradigmas concernentes às bibliotecas, pois essa tecnologia favoreceu o aumento do fluxo e da produção da informação no âmbito global e levou a biblioteconomia a substituir o antigo modelo, que priorizava as grandes coleções e os edifícios majestosos pelo novo modelo, que prioriza o acesso a informação de acordo com as necessidades dos usuários. Essa iniciativa desencadeou uma grande mudança nas bibliotecas com a substituição do modelo centrado na disponibilidade do acervo por um novo modelo centrado na acessibilidade da informação (TARGINO, 2010).

Porém, mesmo diante deste cenário, muitas bibliotecas ainda "estão funcionando largamente dentro do paradigma do acervo cuja proposição remonta, para ficarmos mais pertos da atualidade, pelo menos ao século XVII" (COELHO NETTO, 1996, p. 12). Essas bibliotecas focam-se no acervo, no controle de normas, nas regras e linguagens, concentram seus serviços in loco, entre outras características que só servem para afastá-las de seus usuários.

o primeiro motivo para o abandono do paradigma do acervo é exatamente a queda da ideia do local que mantém o acervo como um local de retiro. Hoje, a informação e a reflexão a partir da informação ocorrem o tempo todo no lugar de trabalho,

\footnotetext{
${ }^{1}$ CASTELLS, Manuel. A sociedade em rede. 2. ed. São Paulo: Paz e Terra, 1999. 617p. (A Era da Informação: economia, sociedade e cultura, v. 1)
} 
dentro de casa, dentro da escola, não há mais um lugar específico para este acervo (COELHO NETTO, 1996, p. 5).

Valentim na década de 90 já fazia uma abordagem acerca deste tema voltada a área da biblioteconomia, em especial as bibliotecas. Ao estudar sobre os paradigmas apontava que a biblioteconomia deveria assumir o novo paradigma para estar em sintonia com as novas demandas do século XXI e precisava refletir sobre a resistência as mudanças, pois essas mudanças eram necessárias para acompanhar a evolução das variadas áreas do conhecimento (VALENTIM, 1995).

É interessante transcrever as diferenças entre os modelos de bibliotecas, construídos por Valentim, em 1995, mas que ainda persistem até hoje:

Quadro 1 - Mudança de paradigmas na biblioteconomia

\begin{tabular}{|c|c|}
\hline Biblioteca Antigo Modelo & Biblioteca Novo Modelo \\
\hline Estrutura hierárquica & Estrutura horizontal \\
\hline Enfoque no acervo & Enfoque na informação \\
\hline Organização estática & Organização dinâmica \\
\hline Trabalho desenvolvido em serviços & Trabalho desenvolvido em projetos \\
\hline Gerenciamento centralizado & Autogerenciamento \\
\hline Conhecimentos específicos & Conhecimentos amplos \\
\hline Relacionamento competitivo & Relacionamento cooperativo \\
\hline Motivação individual & Motivação de equipes \\
\hline Ações controladas & Ações inovadoras \\
\hline Atendimento pessoal & Atendimento remoto \\
\hline Pesquisa in loco & Pesquisa remota \\
\hline Acervo linear & Acervo óptico \\
\hline Linguagem controlada & Linguagem livre \\
\hline Entrada de dados referenciais & Entrada do texto completo \\
\hline Serviços in loco & Serviços on-line \\
\hline Produtos impressos & Produtos automatizados \\
\hline Utilização de sistemas ilhados & Utilização de sistemas integrados \\
\hline Utilização de mídia única & Utilização de multimedia \\
\hline
\end{tabular}

Fonte: adaptado de Valentim (1995)

De acordo com o quadro de Valentim (1995) existem mudanças acentuadas entre o modelo antigo de biblioteca e o novo modelo. Dentre essas mudanças a autora destaca a nova mediação entre o profissional bibliotecário e o usuário, já que o usuário não tem que necessariamente que ir até a biblioteca para acessar ou obter informação porque pode ter 
acesso às redes sem sair de casa e o tratamento da informação com outra roupagem, devido à maioria dos sistemas de informação oferecer texto completo.

Outras abordagens acerca de mudanças de paradigmas podem ser vistas na obra de Malheiro e Ribeiro (2011), onde os autores chamam o antigo paradigma de (custodial, patrimonialista, historicista e tecnicista) e traçam as características do novo paradigma (póscustodial e informacional e científico). Para eles, o paradigma custodial e patrimonialista foi gerado pelo Estado-Nação, posteriormente transformado em Estado Cultural, responsável por gerenciar arquivos, bibliotecas e museus públicos.

Este paradigma é entendido: "como modo de ver e de fazer induzido, desde logo, pela formação, feita ao longo de anos e décadas dos profissionais de arquivo e, também, de biblioteca e ainda, na vertente mais assumidamente tecnicista, dos Centros de Documentação Científica e Técnica (MALHEIRO; RIBEIRO 2011, p. 18).

O paradigma custodial, patrimonialista, historicista e tecnicista possui traços essenciais, como:

\footnotetext{
- Sobrevalorização da custódia ou guarda, conservação e restauro do suporte, como função basilar da atividade profissional de arquivistas e bibliotecários;

- Identificação do serviço/missão custodial e público de Arquivo e de Biblioteca, com a preservação da cultura "erudita", "letrada", ou "intelectualizada" (as artes, as letras e as ciências), em antinomia mais ou menos explícita, com a cultura popular, "de massas" e de entretenimento;

- Enfatização da memória como fonte legitimadora do Estado-Nação e da cultura como reforço identitário do mesmo Estado e respectivo Povo, sob a égide de ideologias de viés nacionalista;

- Importância crescente do acesso ao "conteúdo", através de instrumentos de pesquisa (guias, inventários, catálogos e índices) dos documentos e do aprofundamento dos modelos de classificação e indexação, derivados do importante legado tecnicista e normativo dos belgas Paul Otlet e Henri La Fontaine, com impacto na área da documentação científica e técnica, possibilitando a multiplicação de Centros e Serviços de Documentação/Informação, menos vocacionados para custódia e mais para a disseminação informacional;

- Prevalência da divisão e assunção profissional decorrente da criação e desenvolvimento dos serviços/instituições Arquivo e Biblioteca, indutora de um arreigado e instintivo espírito corporativo que fomenta a confusão entre profissão e ciência (persiste a ideia equívoca de que as profissões de arquivista, de bibliotecário e de documentalista geram,naturalmente, disciplinas científicas autônomas como a Arquivística, a Bibliotecologia/ Biblioteconomia ou a Documentação) (MALHEIRO; RIBEIRO 2011, p. 34,35).
}

Ainda segundo Malheiro e Ribeiro (2011), esse paradigma reflete o modo de ver e de agir dos profissionais da documentação/informação, que se confrontam com as mudanças acentuadas pela emergência de um novo paradigma pós-custodial e informacional e científico. Essa contradição profunda aponta para uma crise deste paradigma custodial e tecnicista onde processos e procedimentos são modificados ou substituídos. Neste contexto, atividades como 
a guarda e a patrimonialização de documentos deixam de ser primordiais e cedem lugar a coleta, seleção e acesso as fontes de informação, desencadeando assim uma nova era, a era da informação do paradigma pós-custodial.

O paradigma pós-custodial e informacional e científico foi fomentado e intensificado pelo impacto da era da informação (a partir de 1945) e pela conjuntura internacional da Rede. Este paradigma está emergindo entre os profissionais da informação e já está afetando a formação destes profissionais. É um novo modo de ver, pensar e de agir, pós custodial, informacional e científico, Malheiro e Ribeiro (2011, p. 58-60) traçam suas características essenciais:

Valorização da informação enquanto fenômeno humano e social, sendo a
materialização num qualquer suporte um epifenómeno;
Constataça do incessante e natural dinamismo informacional, oposto ao
"imobilismo" documental, traduzindo-se aquele pelo trinômio criação-seleção
natural versus acesso-uso, e o segundo, na antinomia efêmero versus permanência;
Prioridade máxima dada ao acesso à informação, por todos em condições bem
definidas e transparentes, pois só o acesso público justifica e legitima a custódia e a
preservação:
Imperativo de indagar, compreender e explicitar (conhecer) a informação social,
através de modelos teórico-científicos cada vez mais exigentes e eficazes, em vez do
universo rudimentar e fechado da prática empírica composta por um conjunto
uniforme e acrítico de modos /regras de fazer, de procedimentos só aparentemente
"assépticos" ou neutrais de criação, classificação, ordenação e recuperação;
Alteração do atual quadro teórico-funcional da atividade disciplinar e profissional
por uma postura diferente, sintonizada com o universo dinâmico das Ciências
Sociais e empenhada na compreensão do social e do cultural, com óbvias
implicações nos modelos formativos dos futuros profissionais da informação; e
Substituição da lógica instrumental, patente nas expressões "gestão de documentos"
e "gestão da informação, pela lógica científico-compreensiva da informação na
gestão, isto é, a informação social está implicada no processo de gestão de qualquer
entidade ou organização e , assim sendo, as práticas informacionais decorrem e
articulam-se com as concepçôes e práticas dos gestores e atores e com a estrutura e
cultura organizacionais, devendo o cientista da informação, em vez de ou antes de
estabelecer regras operativas, compreender o sentido de tais práticas e apresentar
dentro de certos modelos teóricos as soluções (retro ou) prospectivas mais
adequadas.

No paradigma pós-custodial a utilização das TIC's introduziu novas formas de reprodução e comunicabilidade de conteúdos/informação, contribuindo para que esta coexista em dois ou mais suportes diferentes. Diante disso a informação é reproduzida e posta quantas vezes for necessária, sem limites, a circular. E isto se contrapõe à custódia, guarda (MALHEIRO; RIBEIRO, 2011).

Como pode ser visto, tanto Valentim (1995) quanto Malheiro e Ribeiro (2011) abordam o mesmo tema dos paradigmas, a primeira no âmbito da biblioteconomia, os últimos no âmbito da arquivologia, porém, mesmo em áreas da ciência da informação diferentes, são 
observadas semelhanças do paradigma do acervo com o custodial (prioriza a guarda o patrimônio do documento) e do paradigma da informação com o pós-custodial (prioridade no acesso as fontes de informação).

Outra preocupação dos autores em relação aos paradigmas está relacionada ao perfil do profissional bibliotecário em tempo de mudanças:

\begin{abstract}
Caberá ao profissional bibliotecário criar metodologias de seleção, direcionamento, orientação e antirruídos para o acesso às informações. $\mathrm{O}$ trabalho do bibliotecário será fundamentalmente de "gatekepeer", ou seja, seleção e disseminação de informações, através de redes e bases de dados. O acesso direto do usuário às informações, bem como sua obtenção será facilitada pelo trabalho desenvolvido por esses profissionais, mas aos olhos do usuário serão transparentes (VALENTIM, 1995, p. 5).
\end{abstract}

O Bibliotecário já não é um mediador dominante, porque tem de partilhar "espaço" com o programador, com o "designer" de informação e ainda com o utilizador [...] Esta pluralidade de mediações não assegura a tranquilidade [...], mas também não implica no apocalipse! (MALHEIRO; RIBEIRO, 2011, p. 177- 178)

De acordo com as citações, há uma grande preocupação dos autores relacionada à função do bibliotecário nesta nova perspectiva paradigmática, mas independente de paradigmas, a frase de Mason $\left(1990^{2}\right.$ apud GUIMARÃES, 1997) é a que melhor define o papel do bibliotecário de hoje e sempre como o profissional que é capaz de fornecer a informação certa, da fonte certa, ao cliente certo, no momento certo, de forma certa e a um custo que justifique seu uso.

\title{
A atuação dos bibliotecários e gestores de bibliotecas frente às mudanças de paradigmas
}

Quando se discutem os novos paradigmas da biblioteca, se espera uma nova postura do bibliotecário. Os bibliotecários atuantes nas bibliotecas primitivas carregavam um perfil insaturado na Idade Média, onde a biblioteca era um lugar de retiro, de isolamento, com acesso permitido apenas a poucos privilegiados, e quem ali atuava era um membro do poder que estabelecia as relações entre o autor e o leitor como intermediário (dono da informação), orientador de leituras (ideologia do poder), um intercessor (censura) (COELHO NETTO, 1996). Porém, com as numerosas transformações sociais, decorrentes dos avanços científicos e tecnológicos, o bibliotecário precisou se adaptar e modificar sua forma de atuação. De

\footnotetext{
${ }^{2}$ MASON, R. O. What is an information professional? Journal of education for library and information science, Arlington, v. 31, n. 2, p. 122-138, 1990.
}

InCID: R. Ci. Inf. e Doc., Ribeirão Preto, v. 5, n. 1, p. 69-89, mar./ago. 2014. 
acordo com Targino (2010, p. 44), para que o bibliotecário sobreviva aos tempos de mudança é necessário:

[...] ir além das tarefas rotineiras, como empréstimo domiciliar, serviço de orientação de usuários e levantamentos bibliográficos on-line para assumir outros encargos, a exemplo da avaliação, planejamento, implantação de redes de informação em empresas industriais; programas de gerenciamento de informação na automação de bibliotecas e instituições congêneres; e edição de revistas técnicocientíficas.

Assim como as tecnologias evoluíram, o trabalho do bibliotecário evolui e se diversifica. Se antes a atividade do bibliotecário restringia-se aos limites físicos de uma biblioteca e de uma coleção, hoje o uso difundido da tecnologia a serviço da informação vai além das barreiras físicas e institucionais. Por isso, o bibliotecário necessita desenvolver meios para tornar a biblioteca atraente e indispensável, utilizando-se das tecnologias para atribuir valor à unidade, uma vez que os usuários tendem a distanciar-se da biblioteca física ao utilizar a internet, resultando no que Cury, Ribeiro e Oliveira (2001, p. 95) apontaram para a independência de recursos tecnológicos que o usuário remoto possui.

Autores como Guimarães (1997) e Mason (1990), desde o século passado, já discutiam o perfil do bibliotecário frente aos novos paradigmas. Segundo os autores os bibliotecários seriam os responsáveis pelo fortalecimento de bibliotecas representativas do século XXI, e, portanto, fortalecidas por paradigmas que se sustentam não apenas no avanço tecnológico, mas na valorização do usuário, requisitos e atribuições.

De acordo com Valentim (2000), para atuar frente aos paradigmas com qualidade o bibliotecário deve ter as seguintes questões definidas: a) remodelagem da unidade/sistema de informação, buscando uma interação profunda entre os atores deste cenário; b) capacitação dos profissionais de informação, buscando o conhecimento necessário para atuar neste cenário; c) vocação definida voltada para serviços informacionais, buscando o encantamento do cliente; d) visualização da unidade/sistema de informação de forma crítica, buscando a melhoria contínua.

Atrelados a esses paradigmas, Targino (2010, p. 44-45) aponta alguns requisitos básicos que o profissional da informação deve ter, são eles: visão gerencial, capacidade de análise, criatividade e atualização. Para a autora a visão gerencial permite ao profissional tomar decisões racionais e eficientes frente a questões estratégicas, ao custo da informação. A capacidade de análise é um pré-requisito para a tomada de decisão diante da diversidade de suportes, á multiplicidade de uso da informação e as diversidades de demandas InCID: R. Ci. Inf. e Doc., Ribeirão Preto, v. 5, n. 1, p. 69-89, mar./ago. 2014. 
informacionais. Algumas atitudes específicas também são citadas pela autora como essenciais, entre elas: noção precisa de tempo e de espaço; conhecimento nos investimentos financeiros e com pessoal, engenharia e administração de fontes de informação e gestão eletrônica de documentos.

Em relação ao requisito criatividade, Targino (2010, p. 45) considera indispensável para qualquer profissional nos dias de hoje, por incluir características cognitivas e perceptivas diante de situações novas, mencionando que "criatividade consiste, fundamentalmente, em buscar novas soluções para velhos problemas".

A capacidade de atualização no processo de educação continuada também é um fator crucial ao bibliotecário, pois requer leitura, estudo e pesquisa que vão além dos conhecimentos técnicos. Conforme Rozados (2007, p. 2), a educação continuada tem grande relevância no exercício da profissão do bibliotecário, pois é por meio dela que se obtêm conhecimentos relacionados à educação para o trabalho.

Em relação às habilidades, o conhecimento das TIC's é considerado como a primeira condição para que os bibliotecários atuem como multiplicadores e alfabetizadores na sociedade. Outras habilidades como a motivação pessoal, o conhecimento de idiomas, o trabalho em grupo, o dinamismo, a persistência, a visão interdisciplinar, o profissionalismo, a capacidade de comunicação, a capacidade em firmar alianças; a competência; a responsabilidade; a capacidade de inovação; também são importantes no trabalho do bibliotecário. Acompanhar os movimentos de democratização da informação, independente de estar vivenciando qualquer paradigma é imprescindível. $\mathrm{O}$ acesso livre se impõe como modalidade de publicação de artigos científicos que cresce de forma veloz, graças aos repositórios de acesso livre e ou a softwares de código aberto (TARGINO, 2010).

Outro ponto a discutir em relação à atuação do bibliotecário é o aspecto administrativo ou gerencial. A complexidade dos sistemas de informação, as mudanças e modernidades a que estão sujeitos hoje, exigem que os bibliotecários conheçam bem as funções administrativas que lhes são atribuídas, fato que é corroborado por Silveira (2009, p. 130) no que tange aos conhecimentos diferenciais exigidos para a administração da biblioteca. 
Fiúza, Paim e Ferreira ( $1987^{3}$ apud SILVEIRA, 2009), afirmam que as habilidades gerenciais se adquirem a partir do conhecimento das bases teóricas de administração e destacam a necessidade de conhecer os variados estilos gerenciais e desenvolver a capacidade de sintetizá-los e aplicá-los a uma instituição específica.

O trabalho em prol da motivação do pessoal e da qualidade de vida na biblioteca são fatores que também devem ser considerados pelo bibliotecário gestor. Martell (1989) diz que o projeto das tarefas pode motivar os empregados, gerando efeito benéfico sobre a satisfação e o desempenho. O autor revela que geralmente os administradores tendem a tratar os empregados como instrumentos ou como extensões das máquinas, ignorando as características singulares do empregado, enquanto indivíduo. Martell (1989) define qualidade de vida no trabalho (QVT), como o grau em que membros da organização de trabalho são capazes de satisfazer importantes necessidades pessoais com suas experiências na organização. Se o empregado sente-se feliz e motivado na biblioteca consequentemente seu desempenho melhora.

A estrutura organizacional das bibliotecas, suas normas, interfere no comportamento e na imagem de seus profissionais, assim como nas possibilidades de acesso aos recursos informacionais nelas armazenados ou disponíveis. Uma estrutura organizacional hierarquizada, mal planejada com normas inflexíveis é causadora da limitação relacionada ao grau de qualidade das bibliotecas em relação às necessidades dos clientes-usuários e da sua própria comunidade de trabalhadores (SILVEIRA, 2009). Já uma estrutura participativa com uma administração profundamente democrática, permitindo aos membros de toda organização manifestar suas opiniões em relação aos caminhos a serem seguidos é essencial para se alcançar o sucesso organizacional.

Diante do exposto entende-se que são os profissionais e os gestores os responsáveis, por excelência, pela qualidade das bibliotecas. O bibliotecário precisa estar atento às mudanças sendo capaz de gerir com eficiência e eficácia a biblioteca, as pessoas e os serviços; utilizando-se das tecnologias necessárias e apropriadas ao gerenciamento eficaz da informação.

\footnotetext{
${ }^{3}$ FIÚZA, M. M.; PAIM, I.; FERREIRA, M. L. A. G. Curso de especialização em administração de bibliotecas universitárias. In: SEMINÁRIO NACIONAL DE BIBLIOTECAS UNIVERSITÁRIAS, 5., Porto Alegre, 1987. Anais... Porto Alegre: Biblioteca Central da UFRGS, 1987. v. 1, p. 47-63.

InCID: R. Ci. Inf. e Doc., Ribeirão Preto, v. 5, n. 1, p. 69-89, mar./ago. 2014.
} 


\section{Material e método}

Essa investigação se insere na área das Ciências Sociais Aplicadas e trata-se de uma pesquisa de natureza exploratória porque proporciona maior familiaridade com o problema com vistas a torná-lo explícito ou a construir hipóteses. Também assume um caráter descritivo e aplicado. Descritivo porque expõe características de determinada população ou o estabelecimento de relações entre variáveis e define sua natureza. Aplicada porque objetiva gerar conhecimentos visando à aplicação prática dirigida à solução de problemas específicos (VERGARA, 2009). A população-alvo foi formada pelos bibliotecários gestores das bibliotecas do SIB /UFPE, sendo eleita a entrevista como instrumento de coleta de dados. O método qualitativo da análise de conteúdo foi utilizado para a análise dos dados, tomando como base o quadro de Valentim (1995).

\section{Caracterização do Sistema Integrado de Bibliotecas}

O SIB/UFPE foi criado com o objetivo de disseminar a informação, democratizar o conhecimento acadêmico e apoiar as atividades de ensino, pesquisa e extensão da UFPE. Tem como missão contribuir para o desenvolvimento científico, tecnológico e cultural de todo cidadão por meio do livre acesso ao seu espaço físico e virtual, apoiando o ensino, a pesquisa a extensão e a gestão, adquirindo e organizando o acesso aos recursos de informação.

Atualmente, o SIB/UFPE é composto por uma Biblioteca Central (BC) e doze Bibliotecas Setoriais, são elas: Biblioteca Central, Biblioteca do Centro Acadêmico do Agreste, Biblioteca Joaquim Cardoso do Centro de Artes e Comunicação, Biblioteca do Colégio de Aplicação, Biblioteca do Centro Acadêmico de Vitória, Biblioteca do Centro de Ciências Biológicas, Biblioteca do Centro de Ciências Exatas e da Natureza, Biblioteca do Centro de Ciências Jurídicas, Biblioteca Centro de Ciências da Saúde, Biblioteca Reitor Edinaldo Bastos do Centro de Ciências Sociais e Aplicadas, Biblioteca Yves Marie Gilles de Maupeou do Centro de Educação, Biblioteca Professor Roberto Amorim do Centro de Filosofia e Ciências Humanas, Biblioteca do Centro de Tecnologia e Geociências.

A biblioteca do Colégio de Aplicação (CAP) não participou desta pesquisa por possuir características divergentes das demais, ou seja, trata-se de uma biblioteca escolar. 


\section{O SIB/UFPE e sua atuação frente aos paradigmas: análise e interpretação}

A entrevista com os gestores foi baseada em 4 eixos que correspondem aos objetivos específicos da pesquisa: realizar um levantamento dos produtos/serviços oferecidos face aos paradigmas do acervo e da informação; observar a gestão dos produtos/serviços frente aos paradigmas; analisar como os gestores direcionam a força de trabalho dos profissionais bibliotecários que atuam no SIB e verificar a qualidade dos investimentos financeiros nas bibliotecas.

Para a análise dos dados, as respostas dos entrevistados foram organizadas, categorizadas e inseridas na perspectiva dos paradigmas do acervo e da informação, com base no quadro de Valentim (1995).

O primeiro eixo procurou identificar quais produtos e serviços as bibliotecas oferecem de modo in loco e de modo on-line. De acordo com os dados, as bibliotecas oferecem in loco: Empréstimos e devoluções de publicações, alerta bibliográfico, orientação à normalização científica de monografias, teses e dissertações, atendimento ao público, consulta, pesquisa e acesso ao acervo, disponibilização de mesas para estudo em grupo e cabines individuais, treinamento do portal de periódicos CAPES e outras bases, disponibilização de laboratório para pesquisa, reprografia, pesquisa bibliográfica, disponibilização de TVs com headphones, exposições, visitas dirigidas, catalogação na fonte, treinamentos das normas da ABNT, serviço de apoio pré-vestibular (pesquisa e orientação), projetos de extensão, sala de projeção de filmes, elaboração de publicações do acervo, atendimento da BDTD.

Quanto aos produtos e serviços on-line, as bibliotecas oferecem: consulta ao portal da Capes, Comut, levantamento bibliográfico; pesquisa, renovação e reserva no catálogo do pergamum, facebook, acesso a internet, consulta às normas da ABNT, livros eletrônicos, catalogação na fonte, disseminação seletiva da informação, sumário de periódicos, twitter, BDTD on-line, indexação de revistas, sugestão de compra.

Dessa maneira, as bibliotecas do SIB oferecem a maioria dos seus serviços de forma presencial. Apesar de algumas possuírem facebook, twitter para comunicação com os usuários e alguns serviços on-line, a maioria das bibliotecas não utiliza as redes sociais.

Diante do exposto, em relação aos produtos e serviços oferecidos pelo SIB fica claro que as bibliotecas oferecem seus serviços como se estivessem numa transição entre o 
paradigma do acervo para o paradigma da informação, porém a ênfase maior ainda está configurada ao modelo antigo de biblioteca, mostrado no quadro de Valentim (1995), onde se prioriza o atendimento pessoal, a pesquisa in loco, os serviços in loco e os produtos impressos.

O segundo eixo abordou a gestão dos produtos e serviços frente aos paradigmas do acervo e da informação, investigando os tipos de suportes oferecidos, a infraestrutura e as preocupações inerentes aos paradigmas.

Em relação aos tipos de suportes as bibliotecas do SIB possuem impressos os seguintes acervos: livros, periódicos, monografias, dissertações, teses, e trabalhos de conclusão de curso. Quanto ao acervo não impresso, as bibliotecas possuem: CDs, DVDs, Fitas VHS, periódicos, teses, dissertações, livros, microfilmes, slides, partituras, disquetes e normas da ABNT.

De acordo com Valentim (1995), que compara os modelos de biblioteca, o acervo linear e a mídia única são características de bibliotecas do antigo modelo e o acervo óptico e multimídia caracterizam as bibliotecas do novo modelo. Apesar das bibliotecas do SIB possuírem uma boa diversidade de materiais não impressos, esses materiais são insignificantes quando comparados ao acervo impresso.

Em relação a infraestrutura, os gestores disseram que as bibliotecas do SIB não possuem uma boa infraestrutura e apontaram problemas como: falta de materiais e equipamentos, espaço físico insuficiente, falta de manutenção, falta de acessibilidade, rede instável, instalações prediais e leiaute inadequados, acústica comprometida.

O problema da infraestrutura inadequada e sem qualidade compromete diretamente os serviços disponibilizados pelas bibliotecas da UFPE. Pelos relatos percebe-se um oferecimento de coleções digitais e de materiais multimídias, porém, não há equipamentos adequados para a utilização e acesso dessas coleções. Esse é um indicador de que o investimento precisa ser estudado para suprir essas deficiências.

Cunha (2000), diz que a biblioteca deve avaliar cuidadosamente o seu espaço, considerando os requisitos do programa de disponibilidade da informação que combinará, por alguns anos, o uso tradicional do suporte em papel com a ampla gama dos suportes digitais e do crescimento do ensino à distância. $\mathrm{O}$ autor explica que o prédio da biblioteca precisa agregar os elementos que fazem uma biblioteca funcionar em um ambiente de rápida mudança 
e, ao mesmo tempo, manter-se como o centro intelectual do campus. A biblioteca deve ter equipamentos para acesso as suas coleções e prover pontos de acesso onde o usuário tenha a possibilidade de ligar seu equipamento portátil e utilizar o sistema para acessar a informação.

No que se refere à preocupação dos gestores frente aos paradigmas existentes, foi constatado que o foco dos gestores varia entre preocupações referentes ao acervo e preocupações referentes ao acesso à informação. Isso demonstra a transição de paradigmas pela qual as bibliotecas estão passando. Logo, os gestores das bibliotecas precisam atuar desenvolvendo os acervos existentes, mas também não podem esquecer-se de fomentar projetos que facilitem o acesso a informação em todos os âmbitos. De acordo com Valentim (1995), o foco dos gestores não pode estar voltado apenas à oferta de documentos e ao desenvolvimento físico das coleções. A biblioteca hoje tem a função de compartilhar e dar acesso às informações independente de sua localização física e de acordo com as necessidades dos usuários.

O terceiro eixo observou como os gestores direcionam a força de trabalho dos profissionais bibliotecários que atuam no SIB.

Em relação a estrutura administrativa, verificou-se que as bibliotecas possuem uma estrutura hierarquizada. Valentim (1995), diz que a transição de uma estrutura administrativa hierárquica para uma estrutura administrativa horizontal é uma característica da mudança de paradigmas dentro da biblioteca. Avaliando por esta ótica, as bibliotecas do SIB neste aspecto estariam atuando dentro da perspectiva do paradigma do acervo.

Quanto ao desenvolvimento dos trabalhos, a maioria dos gestores citou que as bibliotecas desenvolvem seus trabalhos em cima da demanda dos serviços. Poucos são os gestores que desenvolvem os trabalhos baseados em projetos. Sobre esse tema Valentim (1995), aponta que os trabalhos baseados em projetos são característicos das bibliotecas atuantes no paradigma da informação. Segundo Heermann, Costa e Matias (2000, p. 7), o modelo usual da maioria das bibliotecas universitárias é:

Não possuir estratégias próprias, e agir em função das demandas, muitas vezes desorganizadas, provenientes dos diversos grupos existentes dentro da universidade. Esta falta de identidade faz diferença no reconhecimento da biblioteca como órgão no mesmo nível de importância e status que os demais órgãos da universidade.

Para combater tal inércia e fortalecer a imagem das bibliotecas do SIB é necessário renovação. Os bibliotecários gestores devem planejar seus serviços por meio de projetos atuando de acordo com práticas gerenciais modernas, monitorando constantemente o InCID: R. Ci. Inf. e Doc., Ribeirão Preto, v. 5, n. 1, p. 69-89, mar./ago. 2014. 
ambiente. Uma das maneiras de auxiliar o planejamento é a fomentação de projetos. Os projetos das bibliotecas quando alinhados aos projetos da instituição trarão benefícios tanto para as próprias bibliotecas, que irão contar com as verbas destinadas aos projetos quanto para os usuários que utilizarão seus serviços.

No que se refere ao atendimento, a maioria das bibliotecas focam seu atendimento ao modo presencial. $\mathrm{O}$ atendimento virtual foi citado como foco apenas por dois gestores que deram como exemplo a utilização do facebook como veículo de comunicação.

Cunha (2010) em sua pesquisa diz que o atendimento presencial nas bibliotecas tenderá a decrescer devido ao uso das inúmeras ferramentas disponíveis na chamada Web2. 0 . A biblioteca 2.0 deverá fazer uso, entre outros, do blog, do wiki, podcast, do social bookmarking (ou marcadores sociais) e das redes sociais. O serviço de referência será digital por bate papo em linha, correio eletrônico, redes sociais, telefone celular, telefone via internet e por meio da centenária rede de telefone fixo.

Quanto aos serviços prioritários nas bibliotecas, a maioria dos gestores disse que a prioridade na biblioteca seria o atendimento aos usuários, porem ao explicarem como são distribuídos os funcionários nos setores de trabalho, verifica-se que a maior parte da equipe de bibliotecários fica no processamento técnico. Este fator influencia diretamente na qualidade do atendimento e contradiz o depoimento, pois se há uma preocupação maior com o atendimento, a maioria dos técnicos não poderia estar atuando no processamento técnico.

De acordo com Valentim (1995), uma das características das bibliotecas inseridas no paradigma da informação é a atenção voltada ao usuário, as suas necessidades informacionais. É a compreensão de que a biblioteca só existe para o usuário. Isso não significa descaso com as normas, os processos técnicos, mas também não significa que todos os bibliotecários precisam dedicar-se exclusivamente a essas atividades. Sendo assim, é necessário refletir sobre o papel da biblioteca nesta nova conjuntura e distribuir a equipe de maneira que o usuário não fique sem assistência. A importância de um bibliotecário para auxiliar o usuário em suas pesquisas na biblioteca não é desperdício e sim uma demonstração de respeito.

Em relação aos conhecimentos e ao relacionamento da equipe, a maioria dos entrevistados disse que a equipe possui conhecimentos amplos e que sentem um relacionamento de cooperação entre os indivíduos. De acordo com Valentim (1995), os 
conhecimentos amplos e o relacionamento cooperativo são características da biblioteca que atua no paradigma da informação.

Quanto ao gerenciamento da equipe de trabalho, pelas respostas dos entrevistados percebeu-se que a maior parte dos gestores citam em seus depoimentos características que se aplicam a um autogerenciamento da equipe com ações inovadoras. Outra parte possui características em seus depoimentos de um gerenciamento mais centralizado, com ações controladas e existem gestores que demonstram traços das duas categorias em seus depoimentos. Mais uma vez fica clara a atuação das bibliotecas do SIB no processo de transição de paradigmas.

Em relação à motivação da equipe a maioria dos gestores das bibliotecas do SIB sente que a motivação é maior quando as pessoas estão em equipe do que individualmente. A motivação em equipe também é citada por Valentim (1995) como uma das características da biblioteca atuante no paradigma da informação. A motivação é um fator de grande relevância para a administração contemporânea, pois o trabalho em prol da motivação do pessoal e da qualidade de vida na biblioteca são fatores que devem ser considerados pelo bibliotecário gestor.

O último eixo verificou a questão da qualidade dos investimentos financeiros nas bibliotecas. No que se refere ao orçamento e fontes de recursos disponíveis, os entrevistados disseram que não há um orçamento para cada unidade de biblioteca especificamente. Os entrevistados citaram que existe a verba proveniente do pagamento de multas nas bibliotecas, porém na maioria dos casos quem administra a verba é a direção do Centro onde a biblioteca está lotada e não o bibliotecário gestor. Alguns gestores citaram que trabalham com alguns recursos provenientes de projetos, do Centro (onde estão lotados) e da que vem para todo o Sistema de Bibliotecas.

A questão dos investimentos em bibliotecas é discutida por alguns autores da área de Biblioteconomia, Dib e Silva (2006) apontam que a falta de investimentos das universidades, sejam elas públicas ou privadas, nas bibliotecas, afetam diretamente sua atuação, pois essas unidades dependem de investimentos financeiros das universidades a que estão ligadas e do governo, ficando sua sobrevivência restrita aos parcos recursos recebidos destes órgãos.

Se as bibliotecas não recebem os recursos, logo não conseguem desenvolver seus produtos e serviços de forma adequada, não conseguem montar uma infraestrutura eficiente, 
não conseguem oferecer aos funcionários um ambiente propício ao trabalho e consequentemente não irão satisfazer as necessidades dos seus usuários.

Em relação a aquisição das bibliotecas provenientes dos recursos disponíveis, os entrevistados responderam que a verba oriunda de multa serve para a compra de materiais de expediente, manutenção, pequenos reparos ou emergências. Já a verba oriunda dos recursos do SIB, serve para a compra de livros, equipamento e mobiliário. Porém nota-se nos discursos que há um desequilíbrio estrutural no Sistema de Bibliotecas da UFPE. Onde parte das coordenações das bibliotecas tem o apoio dos gestores dos centros em que estão lotadas para suprir suas carências e a outra parte precisa tirar até do próprio bolso os recursos para suprir as necessidades.

Heermann, Costa e Matias (2000), falam que a maioria das bibliotecas universitárias não possuem estratégias próprias, agem em função das demandas, muitas vezes desorganizadas, provenientes dos diversos grupos existentes dentro da universidade. Esta falta de identidade faz diferença no reconhecimento da biblioteca como órgão no mesmo nível de importância e status que os demais órgãos da universidade.

Para fortalecer a imagem das bibliotecas do SIB e combater o mau uso dos recursos que chegam, os gestores precisam planejar os serviços por meio de projetos, atuando de acordo com práticas gerenciais modernas e monitorando, constantemente, o ambiente. É fundamental ao gestor da biblioteca o apoio dos demais gestores da instituição, tanto nas questões financeiras quanto nas questões políticas, para que a biblioteca caminhe de uma forma harmoniosa e integrada com os objetivos da organização.

\section{Considerações finais}

De acordo com Valentim (1995, p. 1) "a mudança de paradigma é necessária para acompanhar as mudanças provocadas pela tecnologia, ciência, política, economia etc.” Deste modo é imprescindível que a biblioteca esteja atenta para poder se adaptar às novas necessidades advindas das mudanças.

Os resultados obtidos nesta pesquisa revelam que as Bibliotecas do SIB oferecem produtos e serviços, tanto in loco quanto on-line, porém a maioria dos serviços é presencial. 
No que se refere à gestão dos produtos e serviços, verifica-se que as bibliotecas disponibilizam o acervo em suporte impresso e não impresso e que a infraestrutura não atende de forma qualitativa, além disso, constatou-se que os gestores preocupam-se tanto com questões referentes ao acervo quanto com as questões referentes à informação, ficando clara a transição de paradigmas.

Em relação à gestão nas bibliotecas, fica evidente a estrutura hierarquizada, os trabalhos desenvolvidos na perspectiva da demanda dos serviços em detrimento de projetos, o foco no atendimento presencial, nos serviços in loco e a necessidade de priorizar o atendimento ao usuário e de cultivar o conhecimento amplo da equipe.

Dentre os pontos positivos relacionados à gestão podem ser destacados: o relacionamento cooperativo, o autogerenciamento, ações inovadoras e a motivação em equipe.

Em relação à qualidade dos investimentos financeiros no SIB foi constatado que não há orçamento específico e que as verbas são utilizadas para suprir necessidades básicas e para a aquisição de livros, equipamentos e mobiliários. Dib e Silva (2006) apontam que a falta de investimentos das universidades, sejam elas públicas ou privadas, nas bibliotecas, afetam diretamente sua atuação, pois essas unidades dependem de investimentos financeiros das universidades, ficando sua sobrevivência restrita aos parcos recursos recebidos destes órgãos.

Os gestores de bibliotecas devem empenhar-se na captação de recursos, tanto da Universidade como também de outras instituições, elaborando projetos e planejando ações. É fundamental o apoio do reitor, das pró-reitorias, coordenações e outros setores nos projetos das bibliotecas para melhorar a qualidade da administração.

Diante do exposto acredita-se que os resultados desta pesquisa mostram que as bibliotecas do SIB possuem características de atuação tanto no paradigma do acervo como no paradigma da informação, porém algumas características demonstram que o velho paradigma ainda é dominante. Sendo assim é importante atentar para o fato de que as bibliotecas que transitam de um paradigma para o outro precisam planejar parte do seu investimento para garantir as necessidades básicas do paradigma anterior, no intuito de não se perder o que foi investido garantindo a memória e o acesso, e a outra parte investir em subsídios para o novo paradigma a fim de manter-se atuante e fortalecer a imagem de provedora e disseminadora da informação.

InCID: R. Ci. Inf. e Doc., Ribeirão Preto, v. 5, n. 1, p. 69-89, mar./ago. 2014. 


\section{Referências}

COELHO NETTO, J. T. Do paradigma do acervo para o paradigma da informação. In: SIMPÓSIO BRASIL-SUL DE INFORMAÇÃO, 1., 1996, Londrina. Anais... Londrina: UEL, 1996. p. 15-30.

CAPURRO, R. Epistemologia e ciência da informação. In: ENCONTRO NACIONAL DE PESQUISA EM CIÊNCIA DA INFORMAÇÃO, 5., 2003, Belo Horizonte. Anais... Belo Horizonte: UFMG, 2003.

CUNHA, M. B. A biblioteca universitária na encruzilhada. DataGramaZero: Revista de Ciência da Informação, v. 11, n. 6, dez. 2010.

Construindo o futuro: a biblioteca universitária brasileira em 2010. Ciência da

Informação, Brasília, v. 29, n. 1, p. 71-89, jan./abr. 2000. Disponível em:

<http://revista.ibict.br/ciinf/index.php /ciinf/article/view/269/237>. Acesso em: 17 mar. 2009.

CURY, M. C.; RIBEIRO, M. S. P.; OLIVEIRA, N. M. Bibliotecário universitário: representações sociais da profissão. Informação \& Sociedade, João Pessoa, v. 11, n. 1, p. 8698, 2001.

DIAS, M. M. K. Formação e desenvolvimento de coleções de serviços de informação. São Carlos: EDUFSCar, 2003.

DIB, S. F.; SILVA, N. C. Unidade de negócio em informação - UNINF: o futuro das bibliotecas universitárias na sociedade do conhecimento. Perspectiva em ciência da informação, Belo Horizonte, v. 11 n. 1, p. 20-31, jan./abr. 2006.

GONZÁLEZ, F. ¿Que es un paradigma?: análisis teórico, conceptual y psicolingüístico del término. Investigación y Postgrado, Caracas, v. 20, n. 1, p. 1, abr. 2005.

GUIMARÃES, J. A. C. Moderno profissional da informação: elementos para sua formação no Brasil. Transinformação, Campinas, v. 9, n. 1, p. 124-140, jan./abr. 1997.

HEERMANN, V.; COSTA, M. D.; MATIAS, M. As bibliotecas universitárias e seus paradigmas: a missão, o ensino, a pesquisa, os custos, o pessoal. In: SEMINÁRIO NACIONAL DE BIBLIOTECAS UNIVERSITÁRIAS, 11., 2000, Florianópolis. Anais... Florianópolis: UFSC, 2000. 1 CD-ROM.

KUHN, T. S. Estrutura das revoluções científicas. 7. ed. São Paulo: Perspectiva, 2003.

MALHEIRO, A.; RIBEIRO, F. Paradigmas, serviços e mediações em Ciência da Informação. Recife: Néctar, 2011.

MARTELL, C. Achieving high performance in library work. Library Trends, Urbana, v. 38, n. 1, p. 73-91, Summer 1989.

MASON, R. O. What is an information professional? Journal of Education for Library and Information Science, Arlington, v. 31, n. 2, p. 122-138, 1990. 
MORIGI, V. J.; SOUTO, L. R. Entre o passado e o presente: as visões de biblioteca no mundo contemporâneo. Revista ACB: Biblioteconomia em Santa Catarina, Florianópolis, v. 10, n. 2, p. 189-206, jan./dez. 2005.

ROZADOS, H. B. F. O bibliotecário brasileiro e a formação continuada: a ação do Conselho Federal de Biblioteconomia. In: CONGRESO IBEROAMERICANO DE BIBLIOTECOLOGÍA, 2., 2007, Buenos Aires. [Anais...] Disponível em: $<$ http://www.cfb.org.br/html/sala_leitura/arquivos/Congreso_Bibliotecologia.pdf $>$. Acesso em: 20 nov. 2012.

SANTOS, M. P. Competência informacional: um estudo com os professores associados I do Centro de Tecnologia da UFPB. 2010. 186 f. Dissertação (Mestrado em Ciência da Informação) - Universidade Federal da Paraíba, João Pessoa, 2010.

SARACEVIC, T. Interdisciplinary nature of information science. Ciência da Informação, Brasília, v. 24, n. 1, p. 36-41, 1995.

SILVEIRA, J. G. Gestão de recursos humanos em bibliotecas universitárias: reflexões. Ciência da Informação, Brasília, v. 38, n. 2, p. 126-141, maio/ago. 2009. Disponível em: <http://revista.ibict.br/ciinf/index.php/ciinf/article/view/1072/1328>. Acesso em: 17 set. 2012.

TARGINO, M. G. A biblioteca do século XXI: novos paradigmas ou meras expectativas? Informação \& Sociedade, João Pessoa, v. 20, n. 1, p. 39-48, jan./abr. 2010.

VALENTIM, M. L. P. Assumindo um novo paradigma na Biblioteconomia. Informação \& Informação, Londrina, v. 0, n. 0, p. 2-6, jul./dez. 1995.

O moderno profissional da informação: formação e perspectiva profissional.

Encontros Bibli: Revista de Biblioteconomia e Ciência da Informação, Florianópolis, n. 9, jun. 2000.

VERGARA, S. C. Projetos e relatórios de pesquisa em administração. 11. ed. São Paulo: Atlas, 2009. 